\section{OPEN ACCESS}

Edited by:

Marisa Gilles,

Western Australian Center for Rural Health (WACRH), Australia

Reviewed by:

Dong Liu,

Western University, Canada

Muhamad Khairulbahri,

Bandung Institute of

Technology, Indonesia

Siqin Wang,

The University of

Queensland, Australia

*Correspondence:

Charbel El Bcheraoui

el-bcheraouic@rki.de

Specialty section

This article was submitted to

Public Health Policy,

a section of the journal

Frontiers in Public Health

Received: 01 September 2021

Accepted: 20 January 2022

Published: 25 February 2022

Citation:

Uthman $O A$, Adetokunboh $0 O$

Wiysonge CS, Al-Awlaqi S, Hanefeld J

and El Bcheraoui C (2022)

Classification Schemes of COVID-19

High Risk Areas and Resulting

Policies: A Rapid Review.

Front. Public Health 10:769174.

doi: 10.3389/fpubh.2022.769174

\title{
Classification Schemes of COVID-19 High Risk Areas and Resulting Policies: A Rapid Review
}

\section{Olalekan A. Uthman ${ }^{1}$, Olatunji O. Adetokunboh ${ }^{2,3}$, Charles Shey Wiysonge ${ }^{4}$, Sameh Al-Awlaqi ${ }^{5}$, Johanna Hanefeld ${ }^{6}$ and Charbel El Bcheraoui ${ }^{5 *}$}

${ }^{1}$ Warwick Centre for Global Health Research, The University of Warwick, Coventry, United Kingdom, ${ }^{2}$ South African Centre for Epidemiological Modelling and Analysis, Stellenbosch University, Stellenbosch, South Africa, ${ }^{3}$ Division of Epidemiology and Biostatistics, Department of Global Health, Stellenbosch University, South Africa, ${ }^{4}$ Cochrane South Africa, South African Medical Research Council, Cape Town, South Africa, ${ }^{5}$ Evidence-Based Public Health, Centre for International Health Protection, Robert Koch Institute, Berlin, Germany, ${ }^{6}$ Centre for International Health Protection, Robert Koch Institute, Berlin, Germany

The COVID-19 pandemic has posed a significant global health threat since January 2020. Policies to reduce human mobility have been recognized to effectively control the spread of COVID-19; although the relationship between mobility, policy implementation, and virus spread remains contentious, with no clear pattern for how countries classify each other, and determine the destinations to- and from which to restrict travel. In this rapid review, we identified country classification schemes for high-risk COVID-19 areas and associated policies which mirrored the dynamic situation in 2020, with the aim of identifying any patterns that could indicate the effectiveness of such policies. We searched academic databases, including PubMed, Scopus, medRxiv, Google Scholar, and EMBASE. We also consulted web pages of the relevant government institutions in all countries. This rapid review's searches were conducted between October 2020 and December 2021. Web scraping of policy documents yielded additional 43 country reports on high-risk area classification schemes. In 43 countries from which relevant reports were identified, six issued domestic classification schemes. International classification schemes were issued by the remaining 38 countries, and these mainly used case incidence per 100,000 inhabitants as key indicator. The case incidence cut-off also varied across the countries, ranging from 20 cases per 100,000 inhabitants in the past 7 days to more than 100 cases per 100,000 inhabitants in the past 28 days. The criteria used for defining high-risk areas varied across countries, including case count, positivity rate, composite risk scores, community transmission and satisfactory laboratory testing. Countries either used case incidence in the past 7, 14 or 28 days. The resulting policies included restrictions on internal movement and international travel. The quarantine policies can be summarized into three categories: (1) 14 days self-isolation, (2) 10 days self-isolation and (3) 14 days compulsory isolation.

Keywords: COVID-19, high-risk areas, travel restrictions, travel ban, classification schemes 


\section{INTRODUCTION}

COVID19 is caused by severe acute respiratory syndrome coronavirus 2 (SARS-CoV-2) (1). As of July 1, 2021, it had infected over 182 million people worldwide and with more than 3.9 million people dead. Initial WHO recommendations regarding travel restrictions was in line with the International Health Regulation (IHR) not to restrict travel (2). Globally, responses have been swift and in full influenza pandemic control mode (3-8). Travel-related control measures comprised different interventions, including the complete closure of national borders to entry or exit, or both; full or partial travel restrictions across borders (e.g., denial of entry or exit based on the nationality, travel history, health status or other characteristics); entry and exit screening at borders based on symptoms or testing; and quarantine of travelers. These measures have been implemented for all modes of travel, including air, land, and sea (9-12).

Travel-related control measures limit the mobility of potential human carriers of infection when crossing national (and, in principle, also sub-national) borders with the aim of reducing or delaying the spread of an infectious disease across, or within countries $(13,14)$. In addition to implementing measures related to International Health Regulations (IHR), many countries around the world have used different national and international area-specific risk profiling schemes to inform decisions related to COVID-19 response, travels and security $(2,15-20)$. High risk areas classification schemes are systems that categorize countries or areas based on risk alongside the internal and international restrictions required for travel in order to protect the transmission of COVID-19.

The use of travel-related public health interventions to limit the spread of epidemic diseases has a long history. Recently, during the SARS outbreak in 2003, entry screening at national borders was deployed, and airport departure screening procedures were deployed in efforts to contain the Ebola outbreak in West Africa and the Democratic Republic of the Congo between 2014 and 2016 (21). Errett et al. (22) investigated the influence of travel restrictions on the transmission of communicable diseases other than influenza and determined that they were effective in limiting disease spread between countries but did not stop transmission. However, because the transmission properties of influenza differ from those of SARSCoV2, these findings are not directly applicable to SARSCoV2 $(23,24)$. Given the high rates of pre and asymptomatic transmission, certain travel-related interventions may be more appropriate than others in the SARSCoV2 pandemic $(23,24)$. Travel quarantine, for example, may be more effective than entry and departure screening (25).

Although the relationship between mobility, policy implementation, and virus spread remains contentious, policies to reduce human mobility have been suggested to play important role in shaping the transmission dynamics (26-29). However, evidence on how countries have classified each other during COVID-19, and how, in consequence, they have determined the destinations to- and from which to restrict travel is not systematically described. In this rapid review, we identified country classification schemes for high-risk COVID-19 areas and associated policies which mirrored the dynamic situation in 2020 , with the aim of identifying any patterns that could indicate the effectiveness of such policies.

\section{METHODS}

We conducted a scoping review (30) to answer the following questions: (1) "what are the classification schemes of COVID19 high risk areas and resulting policies?" and (2) "what are the drivers of change in classification by country?". According to Grant and Booth (2009) (31), Scoping reviews are "preliminary assessment of potential size and scope of available research literature. Aims to identify nature and extent of research evidence (usually including ongoing research)." It has also been suggested that scoping Reviews are best designed for: "When a body of literature has not yet been comprehensively reviewed, or exhibits a large, complex, or heterogeneous nature not amenable to a more precise systematic review." (32). Numerous scoping reviews have been conducted to examine different aspects of COVID-19 pandemic including but not limited to the role of telemedicine $(33,34)$, facial protection $(35-37)$, impact on maternal and child health $(38,39)$, role of artificial intelligent $(40-42)$, and estimating diagnostic accuracy of tests $(43,44)$.

\section{Eligibility Criteria}

We sought to identify and characterize any published or gray literature that reported any form of COVID-19 high risk area classification schemes and travel-related control measures affecting human travel within or across national borders.

Population: We included studies on human populations (without any age restriction) susceptible to SARS-CoV-2/COVID-19.

Interventions: We included introduction and implementation any travel-related control measures affecting human travel across (international travel control policies) or within (restrictions on internal movement policies) national borders.

Comparator(s): We included a range of possible comparators, such as a counterfactual scenario in which the intervention was not implemented, a complete relaxation of the measure, or a partial relaxation of the measure.

Outcome(s): High-risk areas domestic and international classification schemes.

Types of studies: We considered a broad range of empirical studies whether published or gray literature that reported any form of COVID-19 high risk area classification schemes.

Studies that did not meet the inclusion criteria above were excluded.

\section{Information Sources and Search}

The following electronic databases were searched between October 2020 and December 2021 using appropriate keywords: PubMed, Scopus, Web of Science, and medRxiv (Box 1). In addition, an advanced Google search (using the following URL: https://www.google.com/advanced_search) was implemented to identify gray literatures that are relevant to the review question. The keywords that were used for electronic database search were also applied. To conduct focused searches for all countries in 


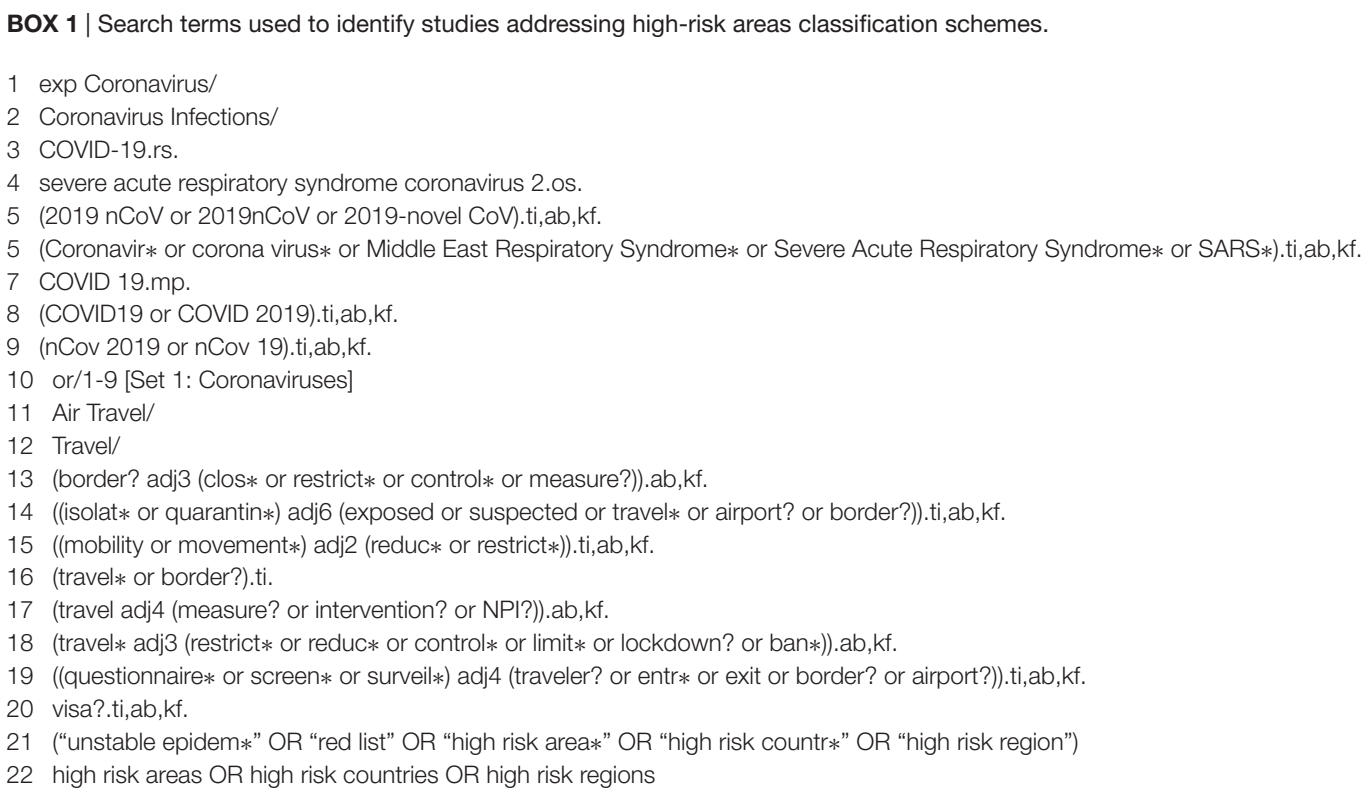

Google, we combined country name with key words related to COVID-19 and high-risk areas.

\section{Study Selection and Data Extraction}

Two authors screened titles and abstracts of publications and websites identified (OAU and OOA). Two authors (OAU and OOA) independently charted key information from the included publications. We extracted data on the following: country, United Nations definition of region, data source (published, unpublished or policy document), policy issued date, types of high-risk areas classifications schemes (domestic classification schemes or international classification schemes), criteria used for classification scheme, resulting policies (restrictions on internal movement policies or international travel controls policies), changes in classification and drivers of changes.

\section{Collating, Summarizing, and Reporting the Results}

Based on the primary research objectives, countries were classified into one of the following categories: type of classification scheme; criteria used for defining high-risk areas; and resulting policy types.

A detailed methodology is available Supplementary Box 1.

\section{RESULTS}

The peer-reviewed literature search yielded 1,784 citations in December 2020, and 3,730 citations in December 2021. After the review of titles and abstracts, we selected 189 full-text articles for critical reading (195 later in December 2021). Only one study, conducted in Mongolia, reported a high-risk area classification scheme and met the inclusion criteria (45). The remaining 188 studies (194 later in December 2021) did not report any form of high-risk area classification scheme. Web scraping yielded policy documents from 43 countries that reported high-risk areas classification schemes. Figure 1 summarizes the search results in a PRISMA flowchart.

Summary classification schemes and resulting policies are shown in Supplementary Table 1. Most of the countries that reported classification schemes were from the European Region $(n=29)$, followed by the Americas $(n=7)$, Asia $(n=5)$, Oceania $(n=2)$, and Africa $(n=1)$. Classification schemes from 13 countries were not reported in detail. The majority of countries introduced international high-risk classification schemes $(n=38)$, while only six countries introduced domestic high-risk classification schemes. The criteria used for defining high-risk areas varied across countries and included: case count, positivity rate, composite risk scores, community transmission, and satisfactory laboratory testing. When reported, the threshold for case incidence (number of confirmed cases per 100,000 inhabitants) varied across the countries. Countries either used case incidence in the past 7 or 14 days.

\section{High-Risk Areas Classification Schemes Domestic Classification Schemes}

Domestic classification schemes were reported by six countries. Of these six, four countries [China, Kosovo, Portugal, and the United Kingdom (UK)] used case counts. The case incidence cut-off also varied across the countries, ranging from 50 cases per 100,000 in inhabitants in the past 14 days to more than 240 cases per 100,000 inhabitants in the past 14 days (Table 1). The remaining two countries were Mexico and Bolivia. Mexico used a composite risk score, while the criterion used by Bolivia is unclear. Effective from July 22, 2020, Mexico introduced four categories of risk areas (maximum, high, moderate or low) using ten epidemiologic indicators. 
Identification of records via databases

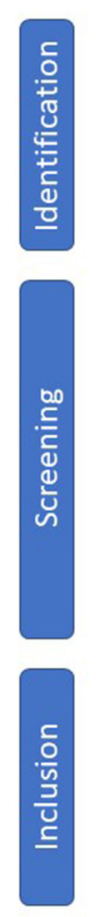

Identification of records via grey literature

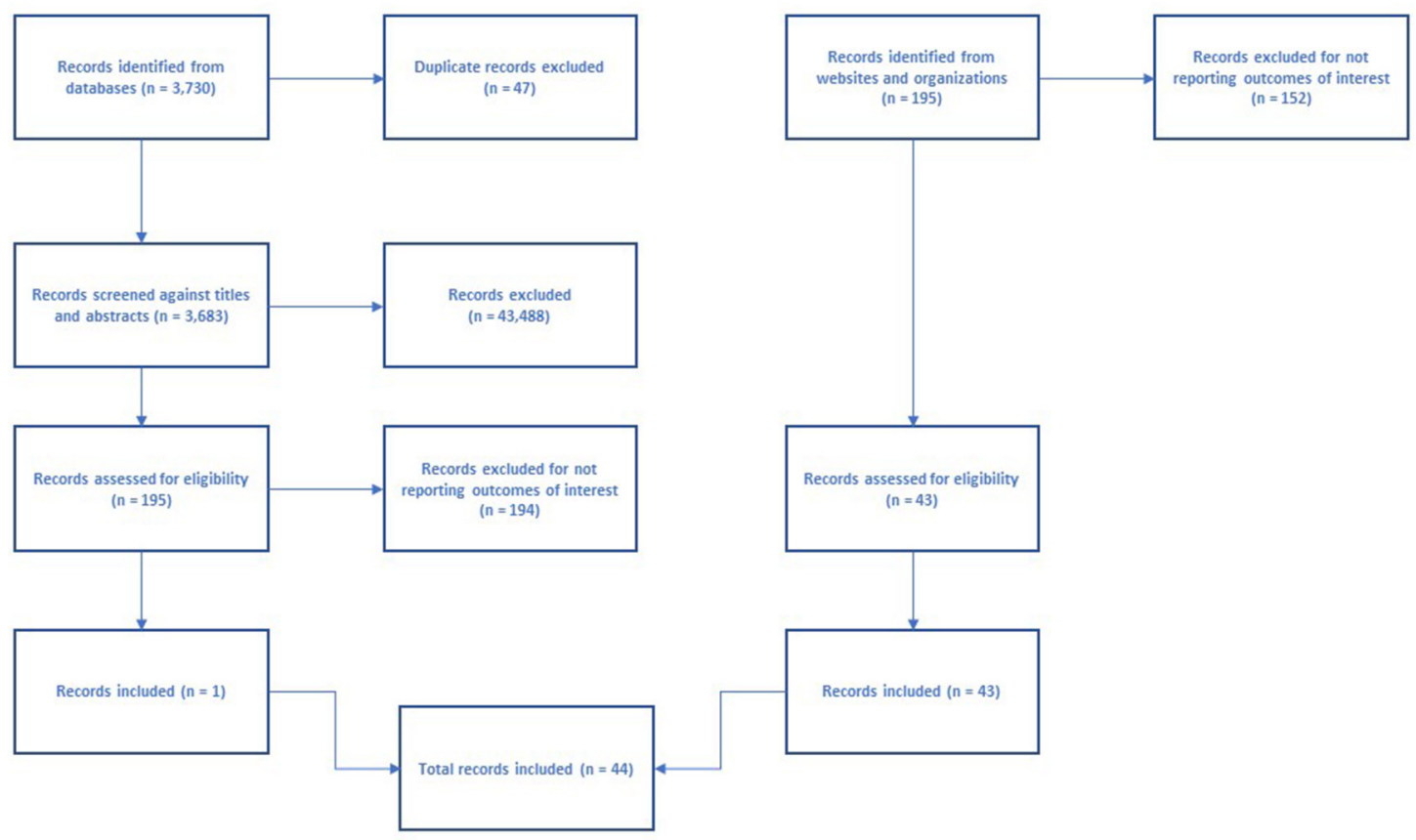

FIGURE 1 | PRISMA flowchart.

\section{International Classification Schemes}

International classification schemes were reported by the remaining 38 countries. The criteria used for defining high-risk areas varied across the countries (Table 1; Supplementary Table 2). However, most used case incidence per 100,000 inhabitants. The case incidence cut-off also varied across the countries, ranging from 20 cases per 100,000 in inhabitants in the past 14 days to more than 500 cases per 100,000 inhabitants in the past 14 days (Table 1). Two countries (Grenada and Moldova) used community transmission rates to define high risk areas. Three countries (Guam, South Africa, and Cyprus) used composite risk scores to define high risk areas. The following countries did not specify criteria used for defining high risk areas: Australia, Austria, Belgium, Brunei, Canada, Malta, Montenegro, Singapore, Slovak Republic, St Vincent and the Grenadines, Trinidad and Tobago and Mongolia.

\section{Resulting Policies}

\section{Restrictions on Internal Movement Policies}

The first internal movement policies due to COVID-19 were issued between January 1, 2020 in Bolivia and November 30, 2020 in Hong Kong (Supplementary Table 3). The trends in different types of restrictions on internal movement as collated by Oxford COVID-19 Government Response Tracker are shown in Figures 2, 3. None of the African countries instituted any restrictions on internal movement between January and February 2020. However, between March 2020 and August 2020, more than
$50 \%$ of the countries restricted internal movement. The trends on pattern of restrictions on internal movement were similar among countries from the Americas and Asia. In Europe and Oceania, restrictions on internal movement were relaxed in many countries starting June 2020.

\section{International Travel Controls Policies}

The first international travel controls policies due to COVID19 were issued between January 1, 2020 in Bolivia, Hong Kong, and Taiwan and August 12, 2020 in Luxemburg (Supplementary Table 3). The trends in different types of international travel control policies as collated by Oxford COVID-19 Government Response Tracker (46) are shown in Figures 4, 5. The trends in pattern of international travel controls were similar among countries from Africa, the Americas and Asia. In Africa, 10 of the 50 countries instituted ban on highrisk regions (20\%), while 38 of the 50 countries (76\%) instituted total border closure after the COVID-19 was declared a pandemic from March 2020. African countries started relaxing the total border closure by August 2020 and by November 2020, only 4 of the 50 countries (8\%) in Africa still instituted total border closure. In the Americas, 27 of the 34 countries (79\%) instituted total border closure after the COVID-19 in April 2020; and similarly, 36 of the 48 Asian countries (75\%) instituted total border closure after the COVID-19 in April 2020. While in Europe, 23 of the 42 countries (55\%) instituted total border closure after the COVID-19 was declared a pandemic from March 2020. However, 
TABLE 1 | Summary of different types of high-risk areas classification scheme.

\begin{tabular}{|c|c|c|c|}
\hline High-risk/red-areas classification scheme & Country & Issued date & Note \\
\hline \multicolumn{4}{|l|}{ Domestic classification schemes } \\
\hline$>50$ infected people per 100,000 in the last 14 days & China & March 23, 2020 & \\
\hline$>100$ infected people per 100,000 in the last 7 days & UK & November 5, 2020 & Traffic light system \\
\hline$>151$ infected people per 100,000 in the last 7 days & Kosovo & November 13, 2020 & \\
\hline$>240$ infected people per 100,000 in the last 14 days & Portugal; & November 24, 2020 & \\
\hline \multicolumn{4}{|l|}{ International classification schemes } \\
\hline$>20$ infected people per 100,000 in the last 14 days & Norway & October 30, 2020 & \\
\hline$>25$ infected people per 100,000 in the last 14 days & Finland & October 10, 2020 & \\
\hline$>40$ infected people per 100,000 in the last 14 days & Slovenia & September 28, 2020 & \\
\hline$>50$ infected people per 100,000 in the last 14 days & Estonia & October 30, 2020 & \\
\hline$>50$ infected people per 100,000 in the last 7 days & $\begin{array}{l}\text { Germany } \\
\text { Denmark }\end{array}$ & $\begin{array}{l}\text { June } 19,2020 \\
\text { September } 25,2020\end{array}$ & \\
\hline$>50$ infected people per 100,000 in the last 28days & US CDC & November 21, 2020 & \\
\hline 50 to 150 infected people per 100,000 in the last 14 days & $E U$ & $\begin{array}{l}\text { Introduced on } 13 \\
\text { October } 2020 \text { and } \\
\text { amended on } 28 \\
\text { January } 2021\end{array}$ & Traffic light system \\
\hline
\end{tabular}

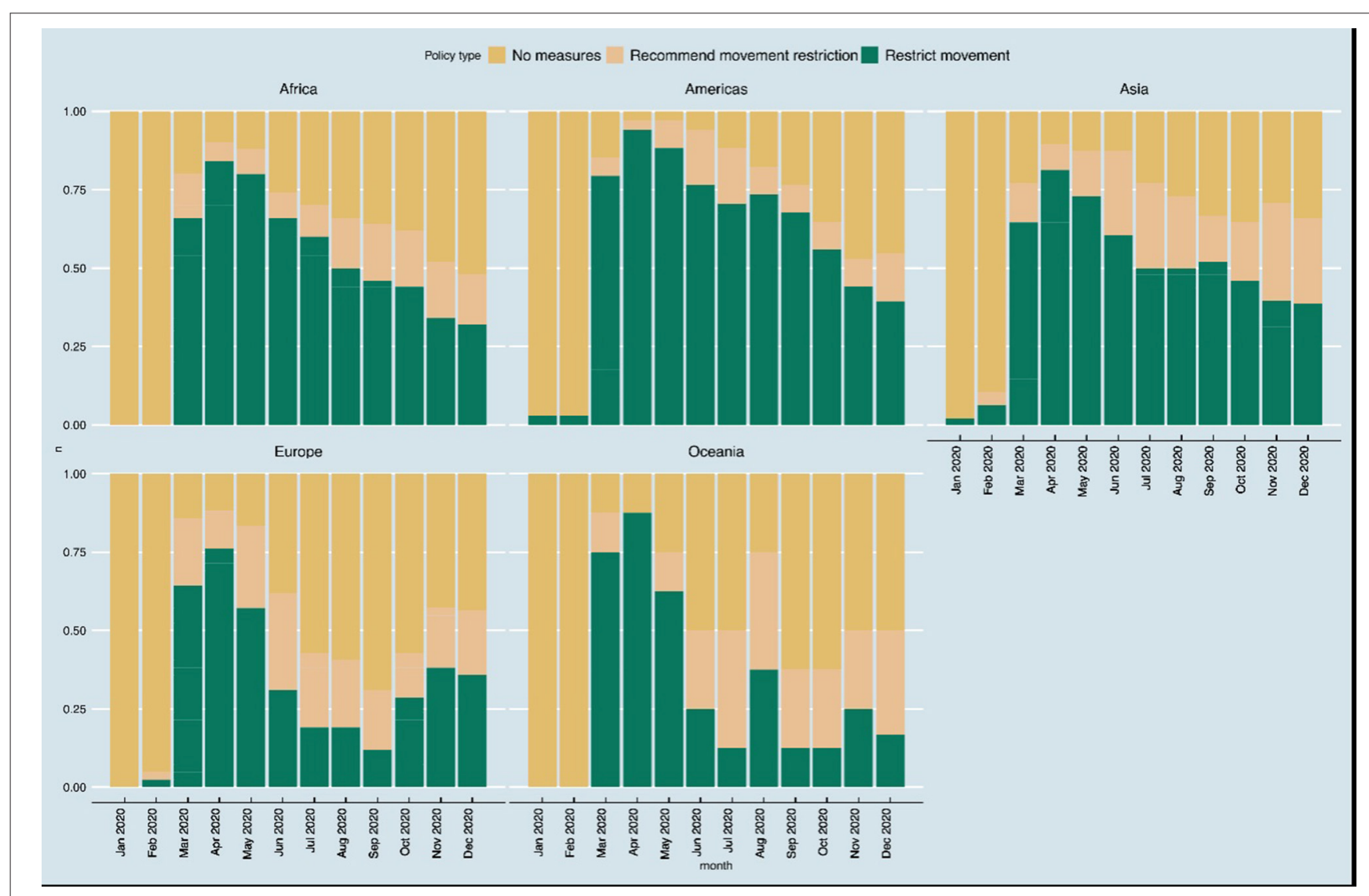

FIGURE 2 | Trends in restrictions on internal movement. 


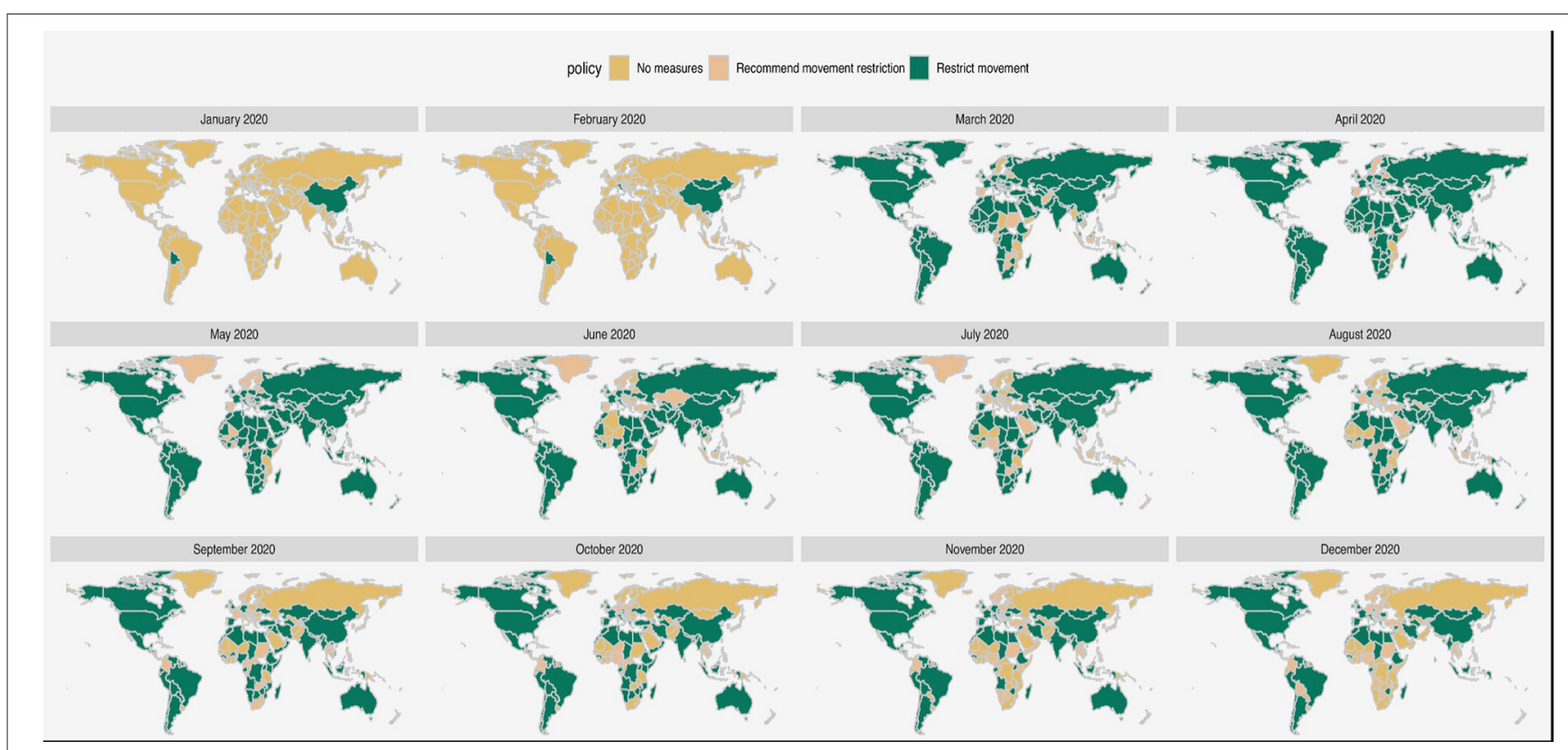

FIGURE 3 | World map of trends in restrictions on internal movement.

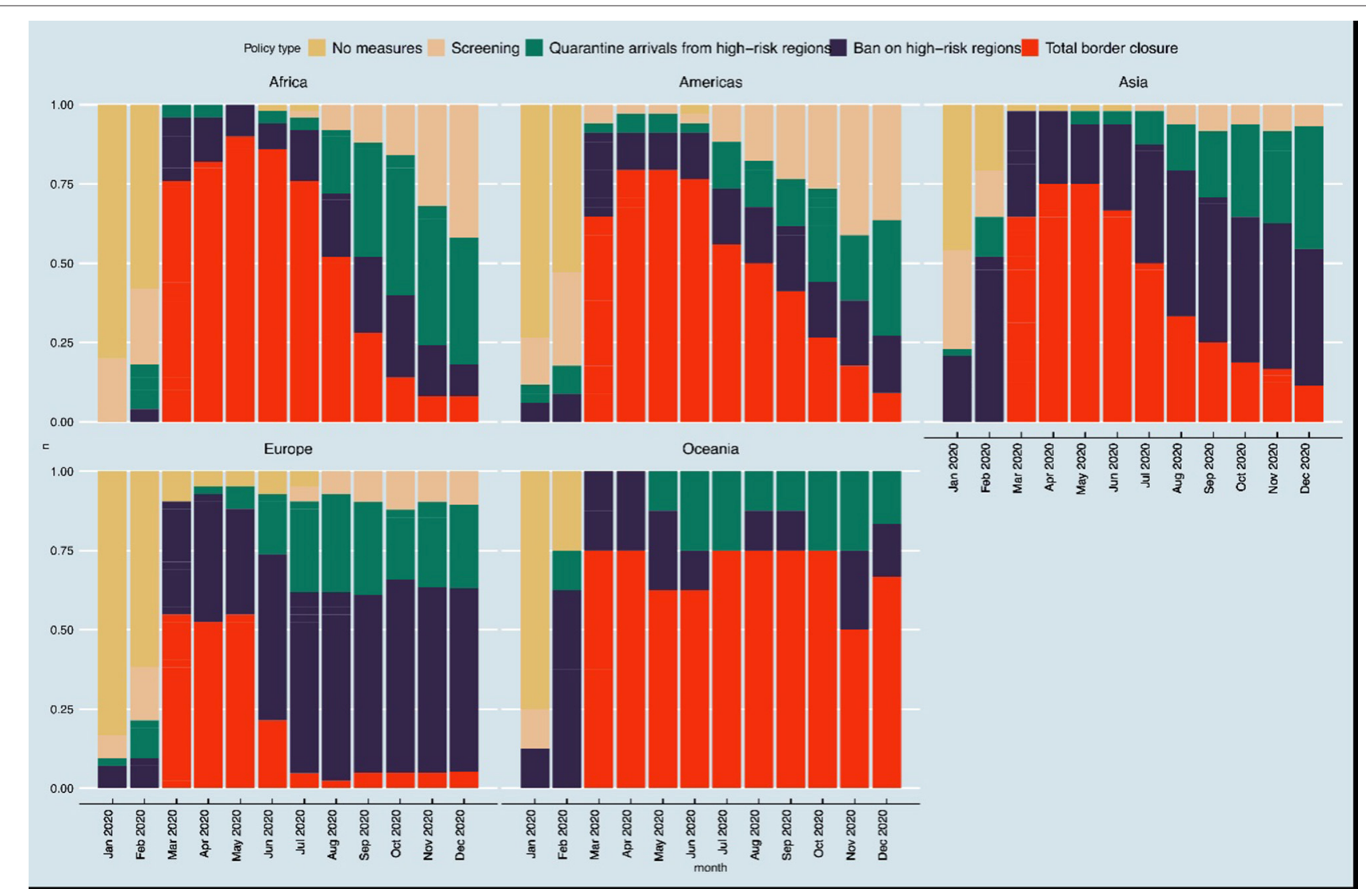

FIGURE 4 | Trends in international travel controls policies. 


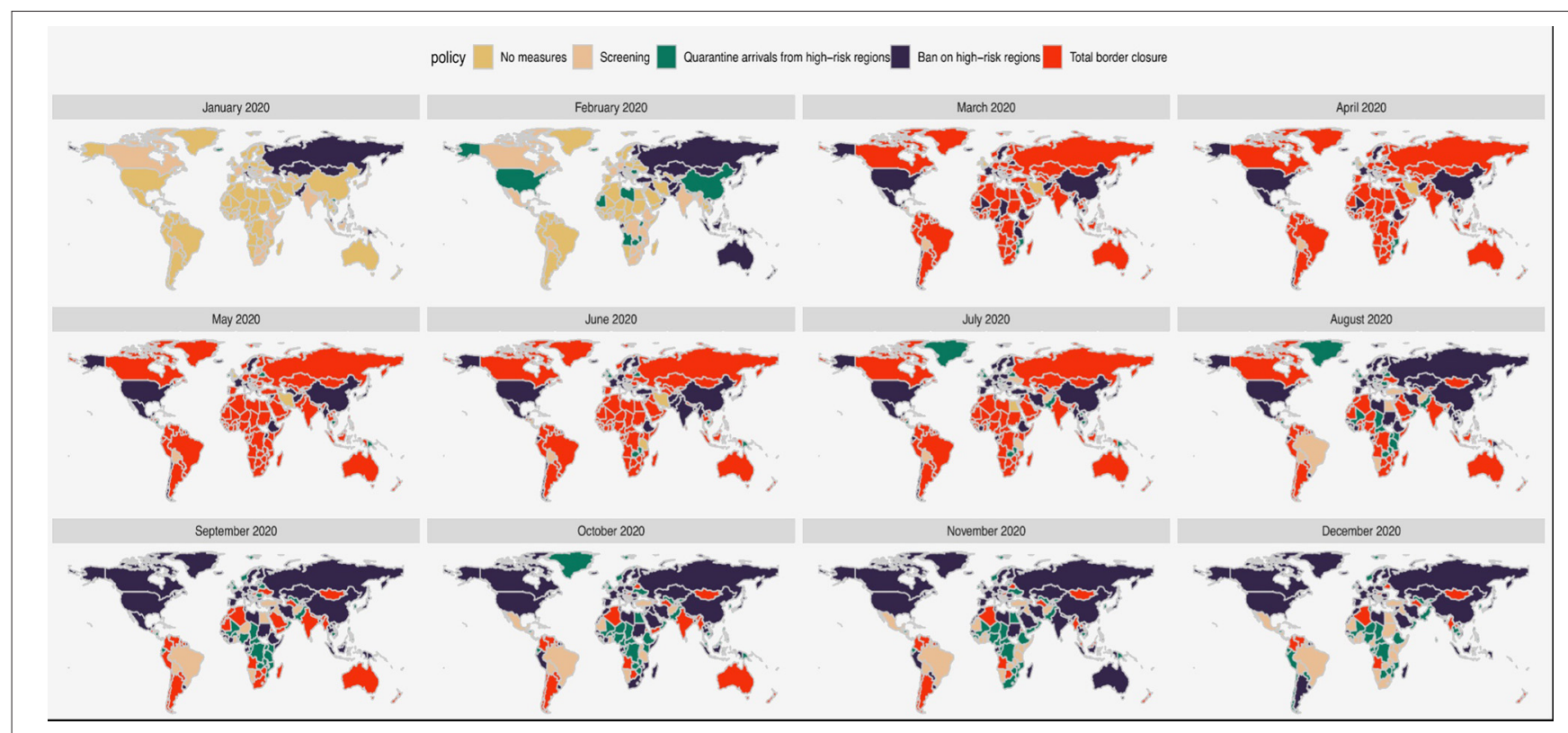

FIGURE 5 | World map of trends in international travel controls policies.

TABLE 2 | Summary of different types of isolation and quarantine policies.

\begin{tabular}{ll}
\hline Policy & Country \\
\hline 14 days self-isolation & Channel Islands of Jersey, Cyprus, Denmark, \\
& Slovenia, Ireland, Italy, Australia, Montenegro, \\
& Trinidad and Tobago and Moldova, Iceland, \\
& Brunei, St Vincent and the Grenadines \\
& China, Malta, Guam, Mongolia, Grenada \\
14 days compulsory isolation & Austria, Finland, Norway, Latvia, Liechtenstein, \\
10 days self-isolation & Lithuania, Luxemburg and Slovak Republic
\end{tabular}

European countries started relaxing the total border closure earlier than other regions, by June 2020, when only 9 of the 42 countries (21\%) still instituted total border closure.

The type of quarantine policies varied across the countries. Table 2 summarized different types of isolation and quarantine policies. The quarantine policies can be summarized into three categories: (1) 14 days self-isolation (Channel Islands of Jersey, Cyprus, Denmark, Slovenia, Ireland, Italy, Australia, Montenegro, Trinidad and Tobago and Moldova, Iceland, Brunei, St Vincent, and the Grenadines); (2) 10 days self-isolation (Austria, Finland, Norway, Latvia, Liechtenstein, Lithuania, Luxemburg, and Slovak Republic); and (3) 14 days compulsory isolation (China, Malta, Guam, Mongolia, Grenada).

\section{DISCUSSION}

We show in this scoping review that many countries adopted different classification schemes for COVID-19 high-risk areas and resulting policies since the beginning of the COVID-19 outbreak. The high-risk COVID-19 areas and associated policies were based on COVID-19 cases estimated to be possibly avoided, number of cases detected and shift in epidemic development due to interventions. Classification schemes for some of the countries were not reported in detail. Most countries in the European Union and North America formulated well-defined high-risk areas classification schemes and travel restriction regulations.

On January 30, 2020, the WHO Director-General declared COVID-19 outbreak a public health emergency of international concern, prompting many countries to adopt international and domestic travel restrictions to prevent importation of COVID-19 infections (47) even before WHO upgrading their declaration to a COVID-19 pandemic on March 11, 2020 (48).

First, countries needed classification schemes for other countries, and for their own geographic organization, to determine the risk of international and domestic travel, and consequent measures. We documented classification schemes of COVID-19 high-risk areas and resulting policies either as they relate to international travel or domestic movement for 43 countries. These were issued between March and November 2020. Most of the 43 countries used case counts as the main criteria for classifying high-risk areas. It has been wellreported previously that apparent case rates are a function of testing rates. Stephen and colleagues (49) have' cautioned that policy should not be based on such a metric which is also a function of government policy. Alternative or combined measures should be sought to avoid creating perverse incentives in policy development e.g., penalizing countries with the best testing regimen, test positivity rates are one such attempt at this. Imposing travel restrictions on countries with apparent high case rates could create a perverse incentive for such countries to test less, or to not publicly report testing rates. It may not be plausible for any responsible government to deliberately reduce testing, 
but government commitment to testing does vary by country for practical, financial, and political reasons. Hence, penalizing countries with high apparent rates could provide a disincentive to the roll-out of greater testing, an essential component of pandemic control which proved to be specifically helpful during this first wave of the COVID-19 pandemic (50). Further, how countries develop their classification schemes is also a matter of their political environment and connected to the nature of their response in terms of how assertive it is (51). For instance, a more assertive response generates higher trust, and vice-versa (52).

While the COVID-19 pandemic is highly dynamic, with a wide spectrum of epidemiological variability by country, risk area classification schemes can by their nature not be adapted at the same pace as the pandemic, or in conjunction with the epidemiological variability, by all countries. Some of the countries like Guam and Mexico did not update the high-risk areas classification schemes concerning travels from different destinations for weeks. Placing destination countries on the same level of risk estimation for many weeks despite changes in the number of cases and positivity rates shows non-adoption of datadriven, evidence-based, and scientific approaches to pandemic control. Most countries in the European Union adopted highly dynamic classification schemes that reflected more closely the changes in the pandemic. In parallel, countries also adopted a wide variety of travel policies, mostly divided into border closure, quarantine and screening travelers (53). Very few countries imposed total lockdowns, an intervention avoided for many reasons despite its big potential to reduce infections and deaths by up to $75 \%$ and 38 (54). Further to what can be feasible, travel policies should be in tune with changes in the epidemiological trend of COVID-19. What we've learned though is that the timeliness of implementing such policies, specifically at the beginning of the outbreak, and the degree of compliance, are major factors to their effectiveness (53). At the early stage of the outbreak, travelers coming from high burden countries may import cases and contribute to the local COVID-19 burden (55). The effect of non-restrictive travel may be pronounced in countries or regions with low COVID-19 infection burden and those at the receiving end of a large volume of arrivals from high burden countries (55).

We found that as much as 38 of the 50 countries instituted total border closure after the COVID-19 was declared a pandemic from March 2020; and started relaxing the total border closure by August 2020 and by November 2020. While most of the countries in the Americas instituted total border closure after the COVID19 in April 2020; and similarly, 36 of the 48 Asian countries instituted total border closure after the COVID-19 in April 2020. While in Europe, only about 23 of the 42 countries instituted total border closure after the COVID-19 was declared a pandemic from March 2020. In addition, European countries started relaxing the total border closure earlier than other regions, by June 2020, when only 9 of the 42 countries still instituted total border closure. The degree to which border closure has worked varied by context. Nevertheless, border closure is not enough if not coupled with other physical distancing policies (53). Indeed, a study comparing three Southeast Asian countries during the COVID-19 pandemic shows a relatively higher success of Singapore in controlling the number of cases, as well as fatality rate due to national lockdown and a stronger health system (56).

Virtually every country implemented some form of travel restrictions, however, our findings and a study by Habibi et al. indicated that some of the high-risk areas' classification schemes were developed and implemented without using comprehensive evidence-based criteria $(18,57)$. Countries that implemented total border closures could have tried to assess how selective restriction policies could have had played. For instance, such countries that welcome non-stationary laborers from neighboring countries could have controlled and monitored this flow more closely to strategically plan for similar scenarios in the future. Developing policies for a new disease like COVID-19 requires evidence-based approaches that will include the use of the best available facts and materials that are specific for similar novel infections and with clearly defined outcomes of interest (57). Further, the decision-making process in selecting the policies to be implemented differs greatly between countries. While investigating such process is outside the scope of this work, we note how countries differ I what public health agencies they refer to, whether national or regional. The United States CDC used both primary and secondary criteria to determine different destinations' Travel Health Notice (THN) levels (58) while countries within the European Union/European Economic Area implemented the ECDC guidelines (59). The EU Recommendation on a Structured Approach to Travel Restrictions in the Form of COVID-19 was adopted by Member States on October 13th. This "traffic light" approach categorizes regions in the European Union (EU) and European Economic Area (EEA) as green, orange, red, or gray based on the risk levels associated with COVID-19 (59). On January 28, 2021, a new dark red category was added to the weekly published map for areas where the COVID-19 virus is circulating at very high levels, including due to more infectious variants (59). Aleta et al. show that travel restrictions are likely to be effective measures only in the short term and may be less effective at a later stage and for the elimination of the infection $(15,60)$. In order to have a better control of COVID-19 pandemic, other preventive and control measures such as promotion of the use of face masks, regular handwashing, school closures, and suspension of large public get-togethers should also be place (61). Other measures such as active surveillance and self-isolation of infected persons and their contacts should also be implemented (45).

We found one recent Cochrane review on "International travel-related control measures to contain the COVID-19 pandemic: a rapid review" (25). The review includes 62 studies conducted around the world and at various stages of the pandemic (25). Most of the studies included in this review compared existing travel-related control measures to no restrictions at all (25). Most of the studies found that travel restrictions that reduced or stopped cross-border movement were helpful, though the magnitude of this benefit varied. Furthermore, several studies found no effect (25). Findings from modeling studies showed that $1-53 \%$ of cases can be detected. In addition, testing travelers could lower the number of cases imported or exported, as well as cases discovered. The review also reported that quarantine appeared to be beneficial in all 
the studies, however the magnitude of this benefit varied from small to large effect. Most studies found some benefit from quarantine and border screening. Effects may vary depending on how long they were quarantined and how often they were tested throughout that time. The review concluded that overall, international travel-related control measures, may help to prevent the spread of COVID19 across national borders (25). Cross-border travel restrictions can be beneficial. Travelers who are merely screened for symptoms at borders are likely to miss many cases; testing, while more successful, may also miss cases if done immediately after arrival. A 10-day quarantine can help prevent the spread of COVID-19, and it may be more successful when combined with another intervention like testing, especially if people follow the restrictions (25).

This review has several strengths. Comprehensive searches of several databases and gray literature sources were conducted to identify eligible articles and documents that will result in the highest quality of evidence. Two reviewers independently screened the search outputs and extracted data from included documents. At the same time, this review has some limitations. First, we set out to include all types of publications especially peer-reviewed papers, and to compare the effectiveness of the different classification schemes on the epidemiological evolution. However, only one of the included documents was a peerreviewed published paper. The systematic search for peerreviewed literature did not yield the desired outputs and the included documents were found via random Google searches of several governmental, policy, and travel sites for more than 200 countries and territories. Second, some of the materials were not in the English language and warranted an additional translation process.

Third, some of the official websites on travel restrictions do not keep historic versions of their policies and were not updated, thereby restricting accurate timeline development, as well as policy change analysis. In addition, it was not possible to access the steps or how the countries choose the criteria used for defining high risk areas. Based on the available evidence it was not possible to access the link between types of classification schemes and resulting policies. Formal modeling of the impact of types of classification schemes and resulting policies on the COVID-19 epidemic should be considered.

\section{REFERENCES}

1. Wei M, Yang N, Wang F, Zhao G, Gao H, Li Y. Epidemiology of coronavirus disease 2019 (COVID-19) caused by severe acute respiratory syndrome coronavirus 2 (SARS-CoV-2). Disaster Med Public Health Prep. (2020) 14:796804. doi: $10.1017 / d m p .2020 .155$

2. von Tigerstrom B, Wilson K. COVID-19 travel restrictions and the International Health Regulations (2005). BMJ Glob Health. (2020) 5:e002629. doi: 10.1136/bmjgh-2020-002629

3. Chan HY, Chen A, Ma W, Sze NN, Liu X. COVID-19, community response, public policy, and travel patterns: a tale of Hong Kong. Transp Policy. (2021) 106:173-84. doi: 10.1016/j.tranpol.2021.04.002

4. Han E, Tan MMJ, Turk E, Sridhar D, Leung GM, Shibuya K, et al. Lessons learnt from easing COVID-19 restrictions: an analysis of

\section{CONCLUSION}

There was substantial variation between and within countries in the measures that governments adopted and how quickly they have adopted them in classifying high-risk areas. In 43 countries from which relevant reports were identified, six issues domestic classification schemes. International classification schemes were issued by the remaining 38 countries and mainly used case incidence per 100,000 inhabitants. The case incidence cut-off also varied across the countries, ranging from 20 cases per 100,000 in inhabitants in the past 7 days to more than 100 cases per 100,000 inhabitants in the past 28 days. The resulting policies included restrictions on internal movement and international travel control. The quarantine policies can be summarized into three categories: (1) 14 days self-isolation, (2) 10 days self-isolation and (3) 14 days compulsory isolation.

\section{DATA AVAILABILITY STATEMENT}

The original contributions presented in the study are included in the article/Supplementary Material, further inquiries can be directed to the corresponding authors.

\section{AUTHOR CONTRIBUTIONS}

OU, OA, CW, SA-A, JH, and CE were involved in the conception of the study. OU and OA carried out the searches, data extraction and drafted the paper with contributions from all authors. All authors read and approved the final manuscript.

\section{FUNDING}

This research was commissioned by the Center for International Health Protection, Robert Koch Institute.

\section{SUPPLEMENTARY MATERIAL}

The Supplementary Material for this article can be found online at: https://www.frontiersin.org/articles/10.3389/fpubh. 2022.769174/full\#supplementary-material

countries and regions in Asia Pacific and Europe. Lancet. (2020) 396:152534. doi: 10.1016/S0140-6736(20)32007-9

5. Kakoullis L, Eliades E, Papachristodoulou E, Parperis K, Chra P, Constantinidou A, et al. Response to COVID-19 in Cyprus: policy changes and epidemic trends. Int J Clin Pract. (2021) 75:e13944. doi: 10.1111/ijcp.13944

6. Kang S, Moon J, Kang H, Nam H, Tak S, Cho SI. The evolving policy debate on border closure in Korea. J Prev Med Public Health. (2020) 53:3026. doi: 10.3961/jpmph.20.213

7. Kavaliunas A, Ocaya P, Mumper J, Lindfeldt I, Kyhlstedt M. Swedish policy analysis for Covid-19. Health Policy Technol. (2020) 9:598612. doi: 10.1016/j.hlpt.2020.08.009

8. Takagi H. Government's policy, citizens' behavior, and COVID-19 pandemic. J Med Virol. (2021) 93:1214-6. doi: 10.1002/jmv.26559 
9. Hsiehchen D, Espinoza M, Slovic P. Political partisanship and mobility restriction during the COVID-19 pandemic. Public Health. (2020) 187:1114. doi: 10.1016/j.puhe.2020.08.009

10. Ji $\mathrm{H}$, Tong $\mathrm{H}$, Wang J, Yan $\mathrm{D}$, Liao $\mathrm{Z}$, Kong $\mathrm{Y}$. The effectiveness of travel restriction measures in alleviating the COVID-19 epidemic: evidence from Shenzhen, China. Environ Geochem Health. (2021) 12:118. doi: 10.1007/s10653-021-00920-3

11. Linka K, Peirlinck M, Sahli Costabal F, Kuhl E. Outbreak dynamics of COVID19 in Europe and the effect of travel restrictions. Comput Methods Biomech Biomed Engin. (2020) 23:710-7. doi: 10.1080/10255842.2020.1759560

12. Yin $\mathrm{H}$, Sun T, Yao L, Jiao Y, Ma L, Lin L, et al. Association between population density and infection rate suggests the importance of social distancing and travel restriction in reducing the COVID-19 pandemic. Environ Sci Pollut Res Int. (2021) 28:40424-30. doi: 10.1007/s11356-021-12364-4

13. Tatem AJ, Rogers DJ, Hay SI. Global transport networks and infectious disease spread. Adv Parasitol. (2006) 62:293343. doi: 10.1016/S0065-308X(05)62009-X

14. Vaidya R, Herten-Crabb A, Spencer J, Moon S, Lillywhite L. Travel restrictions and infectious disease outbreaks. J Travel Med. (2020) 27:taaa050. doi: 10.1093/jtm/taaa050

15. Petersen E, McCloskey B, Hui DS, Kock R, Ntoumi F, Memish ZA, et al. COVID-19 travel restrictions and the international health regulations - call for an open debate on easing of travel restrictions. Int J Infect Dis. (2020) 94:88-90. doi: 10.1016/j.ijid.2020.04.029

16. Quilty BJ, Diamond C, Liu Y, Gibbs H, Russell TW, Jarvis CI, et al. The effect of travel restrictions on the geographical spread of COVID19 between large cities in China: a modelling study. BMC Med. (2020) 18:259. doi: 10.1186/s12916-020-01712-9

17. Shi S, Tanaka S, Ueno R, Gilmour S, Tanoue Y, Kawashima T, et al. Travel restrictions and SARS-CoV-2 transmission: an effective distance approach to estimate impact. Bull World Health Organ. (2020) 98:51829. doi: 10.2471/BLT.20.255679

18. Stanhope J, Weinstein P. Travel restrictions and evidencebased decision making for novel epidemics. Med J Aust. (2020) 213:431.e1. doi: 10.5694/mja2.50803

19. Steffen R, Lautenschlager S, Fehr J. Travel restrictions and lockdown during the COVID-19 pandemic-impact on notified infectious diseases in Switzerland. J Travel Med. (2020) 27: taaa180. doi: 10.1093/jtm/taaa180

20. Xue W, Lam C, Yeung HH, Wong CS, Chan VLY, Wong YS. Travel restrictions in the rising COVID-19 pandemic. Hong Kong Med J. (2020) 26:255-7. doi: 10.12809/hkmj208554

21. Mouchtouri VA, Christoforidou EP, An der Heiden M, Menel Lemos C, Fanos M, Rexroth $U$, et al. Exit and entry screening practices for infectious diseases among travelers at points of entry: looking for evidence on public health impact. Int J Environ Res Public Health. (2019) 16:4638. doi: 10.3390/ijerph16234638

22. Errett NA, Sauer LM, Rutkow L. An integrative review of the limited evidence on international travel bans as an emerging infectious disease disaster control measure. J Emerg Manag. (2020) 18:7-14. doi: 10.5055/jem.2020.0446

23. Carraturo F, Del Giudice C, Morelli M, Cerullo V, Libralato G, Galdiero E, et al. Persistence of SARS-CoV-2 in the environment and COVID-19 transmission risk from environmental matrices and surfaces. Environ Pollut. (2020) 265:115010. doi: 10.1016/j.envpol.2020.115010

24. Fears AC, Klimstra WB, Duprex P, Hartman A, Weaver SC, Plante KS, et al. Persistence of severe acute respiratory syndrome coronavirus 2 in aerosol suspensions. Emerg Infect Dis. (2020) 26:2168-71. doi: 10.3201/eid2609.201806

25. Burns J, Movsisyan A, Stratil JM, Biallas RL, Coenen M, Emmert-Fees $\mathrm{KM}$, et al. International travel-related control measures to contain the COVID-19 pandemic: a rapid review. Cochrane Database Syst Rev. (2021) 3:Cd013717. doi: 10.1002/14651858.CD013717.pub2

26. Chinazzi M, Davis JT, Ajelli M, Gioannini C, Litvinova M, Merler $\mathrm{S}$, et al. The effect of travel restrictions on the spread of the 2019 novel coronavirus (COVID-19) outbreak. Science. (2020) 368:395-400. doi: 10.1126/science.aba9757

27. Chu AMY, Tiwari A, Chan JNL, So MKP. Are travel restrictions helpful to control the global COVID-19 outbreak? Travel Med Infect Dis. (2021) 41:102021. doi: 10.1016/j.tmaid.2021.102021
28. Grépin KA, Ho TL, Liu Z, Marion S, Piper J, Worsnop CZ, et al. Evidence of the effectiveness of travel-related measures during the early phase of the COVID-19 pandemic: a rapid systematic review. BMJ Glob Health. (2021) 6:e004537. doi: 10.1136/bmjgh-2020-004537

29. Mateus AL, Otete HE, Beck CR, Dolan GP, Nguyen-Van-Tam JS, Effectiveness of travel restrictions in the rapid containment of human influenza: a systematic review. Bull World Health Organ. (2014) 92:86880. doi: 10.2471/BLT.14.135590

30. Peters MDJ, Marnie C, Tricco AC, Pollock D, Munn Z, Alexander L, et al. Updated methodological guidance for the conduct of scoping reviews. JBI Evid Implement. (2021) 19:3-10. doi: 10.1097/XEB.0000000000000277

31. Grant MJ, Booth A. A typology of reviews: an analysis of 14 review types and associated methodologies. Health Info Libr J. (2009) 26:91108. doi: 10.1111/j.1471-1842.2009.00848.x

32. Peters MD, Godfrey CM, Khalil H, McInerney P, Parker D, Soares CB. Guidance for conducting systematic scoping reviews. Int J Evid Based Healthc. (2015) 13:141-6. doi: 10.1097/XEB.0000000000000050

33. Doraiswamy S, Abraham A, Mamtani R, Cheema S. Use of telehealth during the COVID-19 pandemic: scoping review. J Med Internet Res. (2020) 22:e24087. doi: 10.2196/24087

34. Hincapié MA, Gallego JC, Gempeler A, Piñeros JA, Nasner D, Escobar MF. Implementation and usefulness of telemedicine during the COVID19 pandemic: a scoping review. J Prim Care Community Health. (2020) 11:2150132720980612. doi: 10.1177/2150132720980612

35. Bradford Smith P, Agostini G, Mitchell JC. A scoping review of surgical masks and N95 filtering facepiece respirators: learning from the past to guide the future of dentistry. Saf Sci. (2020) 131:104920. doi: 10.1016/j.ssci.2020.104920

36. Garcia Godoy LR, Jones AE, Anderson TN, Fisher CL, Seeley KML, Beeson EA, et al. Facial protection for healthcare workers during pandemics: a scoping review. BMJ Glob Health. (2020) 5:e002553. doi: 10.1136/bmjgh-2020-002553

37. Jain M, Kim ST, Xu C, Li H, Rose G. Efficacy and use of cloth masks: a scoping review. Cureus. (2020) 12:e10423. doi: 10.7759/cureus.10423

38. Kotlar B, Gerson E, Petrillo S, Langer A, Tiemeier H. The impact of the COVID-19 pandemic on maternal and perinatal health: a scoping review. Reprod Health. (2021) 18:10. doi: 10.1186/s12978-021-01070-6

39. Mascarenhas VHA, Caroci-Becker A, Venâncio K, Baraldi NG, Durkin AC, Riesco MLG. COVID-19 and the production of knowledge regarding recommendations during pregnancy: a scoping review. Rev Lat Am Enfermagem. (2020) 28:e3348. doi: 10.1590/1518-8345.4523.3348

40. Abd-Alrazaq A, Alajlani M, Alhuwail D, Schneider J, Al-Kuwari S, Shah Z, et al. Artificial intelligence in the fight against COVID-19: scoping review. J Med Internet Res. (2020) 22:e20756. doi: 10.2196/20756

41. Adly AS, Adly AS, Adly MS. Approaches based on artificial intelligence and the internet of intelligent things to prevent the spread of COVID-19: scoping review. J Med Internet Res. (2020) 22:e19104. doi: 10.2196/19104

42. Naseem M, Akhund R, Arshad H, Ibrahim MT. Exploring the potential of artificial intelligence and machine learning to combat COVID-19 and existing opportunities for LMIC: a scoping review. J Prim Care Community Health. (2020) 11:2150132720963634. doi: 10.1177/2150132720963634

43. Arevalo-Rodriguez I, Seron P, Buitrago-García D, Ciapponi A, Muriel A, Zambrano-Achig P, et al. Recommendations for SARS-CoV-2/COVID19 testing: a scoping review of current guidance. BMJ Open. (2021) 11:e043004. doi: 10.1136/bmjopen-2020-043004

44. Axell-House DB, Lavingia R, Rafferty M, Clark E, Amirian ES, Chiao EY. The estimation of diagnostic accuracy of tests for COVID-19: a scoping review. J Infect. (2020) 81:681-97. doi: 10.1016/j.jinf.2020.08.043

45. Erkhembayar R, Dickinson E, Badarch D, Narula I, Warburton D, Thomas GN, et al. Early policy actions and emergency response to the COVID19 pandemic in Mongolia: experiences and challenges. Lancet Glob Health. (2020) 8:e1234-e41. doi: 10.1016/S2214-109X(20)30295-3

46. Hale T, Angrist N, Goldszmidt R, Kira B, Petherick A, Phillips T, et al. A global panel database of pandemic policies (Oxford COVID19 Government Response Tracker). Nat Hum Behav. (2021) 5:52938. doi: 10.1038/s41562-021-01079-8

47. World Health Organization. WHO Ramps Up Preparedness for Novel Coronavirus in the African Region. (2020). Available online at: https://www. afro.who.int/news/who-ramps-preparedness-novel-coronavirus-africanregion (accessed December 3, 2020). 
48. World Health Organization. Timeline: WHO's COVID-19 Response. (2020). Available online at: https://www.who.int/emergencies/diseases/novelcoronavirus-2019/interactive-timeline\# (accessed December 03, 2020).

49. Stephens R, Hobbs R, Perera R, Oke J. Should COVID-19 Travel Quarantine Policy Be Based on Apparent New Case Rates? (2020). Available online at: https://www.cebm.net/2020/09/should-covid-19-travel-quarantinepolicy-be-based-on-apparent-new-case-rates/\#: :text=It\%20has\%20been \%20well\%2Dreported,not\%20publicly\%20report\%20testing\%20rates

50. Pozo-Martin F, Weishaar H, Cristea F, Hanefeld J, Schaade L, Bcheraoui CE. Impact of type and timeliness of public health policies on COVID-19 epidemic growth: Organization for Economic Co-Operation and Development (OECD) Member States, January - July 2020. SSRN. (2020). doi: 10.2139/ssrn. 3698853

51. Boin A, t Hart P, Stern E, Sundelius B. The Politics of Crisis Management: Public Leadership Under Pressure. Cambridge: Cambridge University Press (2005).

52. Perlstein SG, Verboord M. Lockdowns, lethality, and laissez-faire politics. Public discourses on political authorities in high-trust countries during the COVID-19 pandemic. PLoS ONE. (2021) 16:e0253175. doi: 10.1371/journal.pone.0253175

53. Bou-Karroum L, Khabsa J, Jabbour M, Hilal N, Haidar Z, Abi Khalil $\mathrm{P}$, et al. Public health effects of travel-related policies on the COVID19 pandemic: a mixed-methods systematic review. J Infect. (2021) 83:41323. doi: 10.1016/j.jinf.2021.07.017

54. Born B, Dietrich AM, Müller GJ. The lockdown effect: a counterfactual for Sweden. PLoS ONE. (2021) 16:e0249732. doi: 10.1371/journal.pone. 0249732

55. Russell TW, Wu J, Clifford S, Edmunds J, Kucharski AJ, Jit M. The effect of international travel restrictions on internal spread of COVID-19. medRxiv. (2020) 43:1354-64. doi: 10.1101/2020.07.12.20152298

56. Khairulbahri M. Lessons learned from three Southeast Asian countries during the COVID-19 pandemic. J Policy Model. (2021) 43:1354-64. doi: 10.1016/j.jpolmod.2021.09.002

57. Habibi R, Burci GL, de Campos TC, Chirwa D, Cinà M, Dagron S, et al. Do not violate the International Health Regulations during the COVID-19 outbreak. Lancet. (2020) 395:664-6. doi: 10.1016/S0140-6736(20)30373-1

58. Centers for Diseases Prevention and Control (CDC). How CDC Determines the Level for COVID-19 Travel Health Notices. (2020). Available online at: https://www.cdc.gov/coronavirus/2019-ncov/travelers/how-level-isdetermined.html (accessed December 03, 2020).

59. European Commission. Adopted Text - Council Recommendation on a Coordinated Approach to the Restriction of Free Movement in Response to COVID-19 Pandemic. (2020). Available online at: https://ec.europa.eu/ info/live-work-travel-eu/coronavirus-response/travel-during-coronaviruspandemic/common-approach-travel-measures-eu_en (accessed December 03, 2020)

60. Aleta $\mathrm{A}, \mathrm{Hu} \mathrm{Q}$, Ye J, Ji P, Moreno Y. A data-driven assessment of early travel restrictions related to the spreading of the novel COVID-19 within mainland China. Chaos Solitons Fractals. (2020) 1:110068. doi: 10.1016/j.chaos.2020.110068

61. Pozo-Martin F, Weishaar H, Cristea F, Hanefeld J, Bahr T, Schaade L, et al. The impact of non-pharmaceutical interventions on COVID-19 epidemic growth in the 37 OECD member states. Eur J Epidemiol. (2021) 36:62940. doi: 10.1007/s10654-021-00766-0

Author Disclaimer: The views expressed in this publication are those of the authors and not necessarily those of the Robert Koch Institute.

Conflict of Interest: The authors declare that the research was conducted in the absence of any commercial or financial relationships that could be construed as a potential conflict of interest.

Publisher's Note: All claims expressed in this article are solely those of the authors and do not necessarily represent those of their affiliated organizations, or those of the publisher, the editors and the reviewers. Any product that may be evaluated in this article, or claim that may be made by its manufacturer, is not guaranteed or endorsed by the publisher.

Copyright (C) 2022 Uthman, Adetokunboh, Wiysonge, Al-Awlaqi, Hanefeld and El Bcheraoui. This is an open-access article distributed under the terms of the Creative Commons Attribution License (CC BY). The use, distribution or reproduction in other forums is permitted, provided the original author(s) and the copyright owner(s) are credited and that the original publication in this journal is cited, in accordance with accepted academic practice. No use, distribution or reproduction is permitted which does not comply with these terms. 